\title{
Estimation of Efficiency of Processing Soil Samples for Pesticide Residues Analysis
}

Gabriella Suszter*1, Árpád Ambrus ${ }^{2}$, Marianna Schweikert Turcu ${ }^{3}$, and Philipp Martin Klaus ${ }^{3}$

${ }^{1}$ Pesticide Residue Analytical Laboratory, Plant Protection and Soil Conservation Service of BAZ County, H-3526 Blaskovics Str. 24, Miskolc, Hungary

${ }^{2}$ Centre for Plant Protection and Soil Conservation, H1118 Budapest, Budaörsi út 141-145, Hungary

${ }^{3}$ Agrochemicals Unit, FAO/IAEA Agriculture and Biotechnology Laboratory, Agency’s Laboratories Seibersdorf, International Atomic Energy Agency, Address, A-1400 Vienna, Austria

\section{ABSTRACT}

The efficiency of four sample-processing methods was tested with eight different types of soils representing the major proportion of cultivated soils. The principle of sampling constant was applied for characterizing the efficiency of the procedures and testing the well-mixed status of the prepared soil. The test material was $14 \mathrm{C}$-labeled atrazine that enabled keeping the random error of

Received September 27, 2005

*Correspondence: Gabriella Suszter, Pesticide Residue Analytical Laboratory, Plant Protection and Soil Conservation Service of BAZ County, H-3526 Blaskovics Str. 24, Miskolc, Hungary; E-mail: suszterga@caracom.hu, Phone: 3646503 420, Fax: 3646503404 
analyses $\leq$ about $1 \%$. Adding water to the soil proved to be the most efficient and generally applicable procedure resulting in about $6 \%$ relative sample processing uncertainty for $20 \mathrm{~g}$ test portions. The expectable error is inversely proportional to the mass of test portion. Smashing and manual mixing of soil resulted in about four times higher uncertainty than mixing with water.

Grinding of soil is applicable for dry soils only, but the test procedure applied was not suitable for estimating a typical uncertainty of processing dry soil samples. Adding dry ice did not improve the efficiency of sample processing.

Key Words: Efficiency of sample processing; Sampling constant; Soil.

\section{INTRODUCTION}

There are numerous publications describing the analytical procedures for determining pesticide residues in soil but very few include detailed information on how the samples were prepared and homogenized before withdrawing the analytical portions, and especially what is the contribution of sample processing to the variability of the results. The procedures reported are briefly described hereunder. The soil samples were most frequently air-dried at room temperature for $24-48 \mathrm{~h}^{[1-4]}$ or

freeze dried. ${ }^{[5-6]}$ Following the drying process the soil samples were sieved at $2 \mathrm{~mm}$ before analysis 
${ }^{[7]}$ and manually mixed or crushed by a mortar, ${ }^{[8]}$ ground, milled with agate balls for $8-10 \mathrm{~h}$ and mixed thoroughly to homogenize each fraction of the sample. ${ }^{[9]}$ The possible loss of volatile pesticide residues was not investigated in these studies. The soil sample, as received, was simply spread, thoroughly mixed manually and its quantity reduced by quartering. ${ }^{[10]}$

Detailed description of preparation of laboratory samples was described by Taylor et al.: ${ }^{[1]}$ bulk samples of 20-25 kg, composed of 80 cores, were tumbled in a concrete mixer for 5 minutes, passed four times through a riffle to obtain about $2.5 \mathrm{~kg}$ laboratory sample, the wet sample was divided into 4 fractions in the laboratory and 100 g portion extracted. Quadruplicate analyses of sub-samples were performed with relative standard deviations of 2.8-4.2\% which indicated that the sample processing error was negligible. The ISO/CD 11464 describes methodology for pre-treatment of samples for physico-chemical analysis including drying $\left(\leq 40{ }^{\circ} \mathrm{C}\right.$ in an oven or in the air, or freeze-dried), crushing the clods and removing stones, foreign materials which are larger than $2 \mathrm{~mm}$ by sieving and hand picking, sub-sampling the laboratory sample, if required. It is emphasized that the described procedures are not applicable if they affect the results of the determination to be made. 
The correct interpretation of the results of field studies carried out to assess the environmental impact of pesticide residues, such as contamination of ground water, ${ }^{[13]}$ the surface runoff, ${ }^{[14-17]}$ long-range transport, ${ }^{[18]}$ persistence and interaction with soil particles, ${ }^{[19,20]}$ bioavailability of bound residues ${ }^{[21,22]}$ require reliable information on the residue content of soil.

The reliability of residue data depends on the contribution of three major phases of the determination process, ${ }^{[23]}$ namely: sampling, S, sample preparation and processing, SP, and analysis, A. The preparation of the test portion, which is extracted, from the laboratory sample consists of two distinct procedures. ${ }^{[24,25]}$ The sample preparation is the procedure used, if required, to convert the laboratory sample into the analytical sample by removal of different parts (in case of soil: the stones, pebbles, remains of plant and other foreign materials etc.) not to be analyzed. During sample processing the bulk sample size is reduced to obtain the analytical sample which is then homogenized by an appropriate procedure (e.g. cutting, grinding, mixing) to obtain a well-mixed matrix from which the test portion can be reproducibly withdrawn for extraction. The uncertainty of the residue analytical results, $S_{R}$, can be estimated based on the general low of error propagation ${ }^{[26]}$ from the uncertainty of sampling, $\mathrm{S}_{\mathrm{S}}$, uncertainty of sample processing, $\mathrm{S}_{\mathrm{SP}}$, uncertainty of the analysis, $\mathrm{S}_{\mathrm{A}}$ : 
$S_{R}=\sqrt{\left(S_{S}\right)^{2}+\left(S_{S P}\right)^{2}+\left(S_{A}\right)^{2}}$

Each phase can be further divided into consecutive steps, and their uncertainty, if quantified,

can be inserted in the equation. The relative uncertainty of results of the analysis of a laboratory sample, $\mathrm{CV}_{\mathrm{Lab}}$, is influenced by the random errors of sample processing, $\mathrm{CV}_{\mathrm{SP}}$ and analysis,

$\mathrm{CV}_{\mathrm{A}}$ :

$C V_{L a b}=\sqrt{C V_{S P}^{2}+C V_{A}^{2}}$

The uncertainty of analysis, $\mathrm{S}_{\mathrm{A}}$, can be conveniently estimated from the results of the recovery

studies carried out with spiked test portions. It includes the uncertainty of all steps which are

performed after the spiking of the test portion. The uncertainty of sample processing cannot be

directly estimated because the random error of analysis always contributes to the variability of the

results. During the validation of the method, the $\mathrm{S}_{\mathrm{SP}}$ can be quantified by ANOVA from the results of replicate analyses of the extracts of several test portions withdrawn from the analytical sample containing field incurred residues or spiked with the test compound(s) before the homogenization.

${ }^{[27]}$ Lyn et al. ${ }^{[28]}$ applied a semi balanced variant of staggered nested design and analyzed duplicate portions of strawberry containing field incurred residues that reduced the number of analysis for making the study economical. Another approach is to determine the sampling constant, $\mathrm{K}_{\mathrm{S}}$, for the process ${ }^{[29]}$ and calculate the uncertainty of sample processing from it for the actual mass of test portions. ${ }^{[30]}$ 
Systematic studies on the uncertainty of sample processing revealed ${ }^{[28,30,31]}$ that the random error of sample processing of plant materials can be very high and may contribute substantially to the combined uncertainty of the results. Other studies performed with plant matrices ${ }^{[28,32-34]}$ indicated that certain compounds may decompose during sample processing at varying extent which can cause significant systematic error as well as increase the variability of the results.

The preliminary tests indicated that processing of soil samples to obtain $20-50 \mathrm{~g}$ test portions may also significantly contribute to the variability of the results of analysis, which is quite likely in view of the widely varying physical and chemical properties of soils.

The objectives of our study were to determine and compare the efficiency of processing soil samples with different kinds of homogenization techniques and to elaborate an efficient processing procedure, which can be reproducibly applied for different types of soils. The systematic and random errors of sample preparation cannot be estimated; therefore their assessment was not included in this study. The chemical stability or physical loss of analytes were not considered either, as they are compound specific and should be studied during method validation. 


\section{MATERIALS AND EQUIPMENT}

\section{Soil Samples}

Soil samples of about $25-30 \mathrm{~kg}$ were collected in heavy-duty polyethylene bags from the upper

15-20 cm layer of agricultural fields, where wheat, maize and sunflower were grown. Some parameters affecting the physical properties of the soils tested are summarized in Table 1.

\section{Equipment}

Laboratory homogenizers: Stephan UM 5 Universal and Tecator 2096; Grinding mill: Cemotec 1090; Laboratory centrifuge: Sigma 4K15; Top load (0.01 g) and analytical (0.00001 g) balances;

Sieving/disintegrating devise: consisting of a baking-dish of $20 \mathrm{~cm} * 35 \mathrm{~cm} * 4 \mathrm{~cm}$ with a fitting stainless steel metal sieve with holes of $5 \mathrm{~mm}$; Sub-sample divider (Fig. 1): stainless steel metal tray: $40 \mathrm{~cm} * 40 \mathrm{~cm} * 2 \mathrm{~cm}$, with a stainless steal metal grid, which divides the tray into 5 small portions $(8 \mathrm{~cm} * 4 \mathrm{~cm})$ and 5 big portions $(8 \mathrm{~cm} * 36 \mathrm{~cm})$; Rolling mixer: P. Haack Multifix; Shakers:

Edmund Bühler SM 25 and Certomat SII; Oven: Memmert 30-200 ${ }^{\circ}$ C; Liquid Scintillation Counter (LSC): Beckman 6000 TA, with Camberra - Packard 20 mL screw-cap polyethylene vials; General 
laboratory glassware.

\section{Chemicals}

Atrazine analytical standard (Chem. Service); ${ }^{14} \mathrm{C}$-ring labeled atrazine standard, (specific activity:

1.6 Mbq/mg, radiochem. purity: $96.5 \%$ ) provided by Syngenta; Standard solution: $0.05 \mathrm{mg} / \mathrm{mL}$ with specific activity of about $3000000 \mathrm{dpm} / \mathrm{mL}$ (disintegration per minute) prepared from cold and

${ }^{14} \mathrm{C}$-labeled atrazine in acetone. The actual specific activity of the solution was determined with

LSC before the tests. Acetone, pesticide grade, Merck; ammonium chloride (analytical grade,

Merck); dry ice, Linde; Ultima Gold high flash-point LSC cocktail for aqueous and non-aqueous samples (Packard Bioscience).

\section{METHODS}

\section{Storage and Preparation of Soil Samples}

The samples were stored in tightly closed polyethylene bags in a dark storeroom at $15-22{ }^{\circ} \mathrm{C}$ ambient temperature. For one test about 1300-1500 g soil as received was pressed through the 5 
mm sieve. The dry soil, which could not be disintegrated on the sieve, was first crushed in porcelain mortar. The pebbles and foreign materials were removed. The sieved material was mixed manually and a portion of $50 \mathrm{~g}$ was taken for spiking with the ${ }^{14} \mathrm{C}$-labeled atrazine containing standard solution.

\section{Treatment of Soil Samples}

A portion of $50 \mathrm{~g}$ prepared soil sample was weighed in a $100 \mathrm{~mL}$ beaker, treated with $1 \mathrm{~mL}$

${ }^{14} \mathrm{C}$-labelled atrazine standard solution spread over the soil surface, and the spiked soil was mixed as well as possible with a glass road. The spiked soil was kept in the fume-hood for 30 minutes to evaporate the solvent. The treated portion was thoroughly mixed with the rest of the prepared soil according to one of the sample processing procedures described below. The weight of the $1 \mathrm{~mL}$ treating solution and the total amount of pre-treated soil sample were recorded, and the actual spiking level in $\mathrm{dpm} / \mathrm{g}$ soil was calculated.

\section{Sample Processing}




\section{Manual mixing}

The spiked and prepared soil were manually mixed on the tray, then the mixture was transferred to a two-liter bottle with screw cap and mixed for 20 minutes on a rolling mixer.

\section{Grinding}

The prepared dry soil was milled, and about $1500 \mathrm{~g}$ ground soil was collected in a two-liter bottle with screw cap. A portion of $50 \mathrm{~g}$ sample was withdrawn and treated with $1 \mathrm{~mL}$ treating solution. The treated and untreated portions were mixed together in the bottle using rolling mixer for 20 minutes.

\section{Chopping in the presence of dry ice}

The spiked and prepared wet soil was placed into the Tecator blender. After the material was mixed for a few second, dry ice was added in small portions. The blending time and amount of dry ice depended on the soil structure and its water content. For $1500 \mathrm{~g}$ soil about $750-1500 \mathrm{~g}$ dry ice and approximately one to three minutes of total blending time were required to achieve free flowing 
powder like material. The homogenized soil sample was transferred into the sub-sample divider tray, covered with aluminum foil to avoid condensation of water from the air and kept at room temperature until the dry ice evaporated.

\section{Mixing with water and blending}

The spiked and prepared soil was placed into the Stephan blender. The water content of the soil was adjusted to about $30-40 \%$ by adding distilled water. The soil-water mixture was let to stand for some seconds and then blended for about 10-30 seconds. The material from the lid, and the wall was transferred back with a large spatula. The consistency of the matrix was examined visually and, if required, more water was added to get a creamy soil pulp. Mincing was continued for about another 10-30 seconds.

\section{Withdrawal of analytical portions}

The homogenized sample was spread uniformLy on the tray of the sub-sample divider by avoiding segregation of the particles, and the metal grid was placed in the tray (Fig. 1). The grid was used to divide the sample into five small and five large segments making possible the 
withdrawal of single increments of five times $20 \mathrm{~g}$ and five times $200 \mathrm{~g}$, respectively. The test portions were collected in pre-weighted centrifuge tubes and Erlenmeyer flasks respectively. The exact weights of the analytical portions were recorded with 0.01 (200 g portions) or 0.001 (20 g portions) gram accuracy.

\section{Extraction}

The $20 \mathrm{~g}$ and $200 \mathrm{~g}$ test portions were mixed with $2.8 \mathrm{~mL}$ and $28 \mathrm{~mL} 0.2 \mathrm{M} \mathrm{NH}_{4} \mathrm{Cl}$ solution, respectively. Then acetone was added in 2:1 solvent/soil ratio, the vessel was tightly closed and shaken for 30 minutes at 200-250 rpm. The frequency of shaking was adjusted, depending on the type of soil, to assure that the total amount of soil was continuously moving in the extraction vessel. After the extraction the soil was let to settle in the bottom of the extraction flask and about $50 \mathrm{~mL}$ extracting solution was transferred to a centrifuge tube and centrifuged for 1 minute. The small test portion was centrifuged directly. Three times $5 \mathrm{~mL}$ aliquots from each extract were transferred into polyethylene LSC vials for the measurement of radioactivity.

\section{Measurement of Radioactivity}


Twelve milliliters of liquid scintillation cocktail was added to the extract, and then the vial was closed tightly with a cap and shaken thoroughly. The radioactivity (dpm) of each vial was determined by liquid scintillation counting for three times five minutes. Each batch included a

${ }^{14} \mathrm{C}$-labeled standard to monitor the counting precision and accuracy. The recoveries were calculated as the ratio of the measured and applied radioactivity. Based on the actually measured average radioactivity the relative uncertainty of the LSC counting was $0.73 \%$.

\section{Assessment of the Efficiency of Sample Processing}

The efficiency of sample processing can be characterized by the sampling constant, $\mathrm{K}_{\mathrm{S} .}{ }^{\left[{ }^{30]}\right.} \mathrm{The}$ sampling constant is defined as the weight of a single increment that must be withdrawn from a well-mixed material to hold the relative sampling uncertainty to $1 \%$ with $68 \%$ level of confidence.

${ }^{[29]}$ It can be applied for describing the random error of sample processing as well:

$$
K_{S}=m \times C V_{S P}^{2}
$$

where $m$ is the weight of a test portion withdrawn as single increment and $\mathrm{CV}_{\mathrm{SP}}$ is the relative uncertainty of sample processing. Where two sets of test portions of widely differing weights $\left(\mathrm{mL}_{\mathrm{g}}\right.$, the weight of large portion, $\mathrm{m}_{\mathrm{Sm}}$, the weight of small portion, and $\mathrm{mL} / \mathrm{m}_{\mathrm{Sm}} \geq 10$ ) is analyzed and the matrix is well mixed, then the sampling constant must be the same (Equation 4). 
$K_{S S m}=K_{S L g}$

Since the average residue concentrations of the small and the large analytical portions in a well-mixed material should be equal $(\mathrm{R})$, the $\mathrm{CV}_{\mathrm{SP}}\left(\mathrm{S}_{\mathrm{SP}}{ }^{2} / \mathrm{R}^{2}\right)$ can be substituted with the standard deviation, $\mathrm{S}_{\mathrm{SP}}$ :

$$
\begin{aligned}
& S_{S P L g}^{2} m_{L g}=S_{S P S m}^{2} m_{S m} \\
& S_{S P L g}^{2}=S_{S P S m}^{2} \frac{m_{S m}}{m_{L g}}
\end{aligned}
$$

The $\mathrm{S}_{\mathrm{SP}}$ can be calculated from the variance of residues measured in the test portions, $\mathrm{V}_{\mathrm{T}}$, and the variance of analysis, $\mathrm{V}_{\mathrm{A}}$, determined from the replicate analyses of the residues in the same extract, provided that the $\mathrm{V}_{\mathrm{T}}$ is significantly larger than $\mathrm{V}_{\mathrm{A}}$ ' at $95 \%$ probability level based on one-tail F-test (Equation 7).

$V_{S P E}=V_{T}-V_{A}{ }^{\prime}$

As the $\mathrm{V}_{\mathrm{A}}$ ' is calculated from the replicate measurements of the analyte in the extract, the $\mathrm{V}_{\mathrm{SPE}}$ must also contain the uncertainty of extraction. This is a significant difference from the determination of $\mathrm{V}_{\mathrm{A}}\left(\mathrm{S}_{\mathrm{A}}^{2}\right)$ from recovery studies as described under equation 1 . The degrees of freedom are calculated in the usual manner: for $\mathrm{V}_{\mathrm{T}}$ it is equal to $\mathrm{h}^{*} \mathrm{n}-1$, and for $\mathrm{V}_{\mathrm{A}}{ }^{\prime}$ is $\mathrm{h}(\mathrm{n}-1)$, where $h$ is the number of test portions withdrawn and $n$ is the number of replicate analyses of the extract of one test portion. 
As the estimation of the variance based on small number of measurements is imprecise, the equality described by Equation 6 should be checked with two-tail F-test. If the ratio of $\mathrm{S}_{\text {SPLg }}^{2}$ and $\mathrm{S}^{2}{ }_{\mathrm{SPS}}\left(\mathrm{m}_{\mathrm{Sm}} / \mathrm{mL}_{\mathrm{g}}\right)$ (either of them can be larger) is smaller than or equal with the critical $\mathrm{F}$ value, the difference is not significant. In this case the homogenized sample can be considered statistically well mixed, and the $\mathrm{K}_{\mathrm{S}}$ can be calculated from the $\mathrm{mL}_{\mathrm{g}}$ and $\mathrm{CV}_{\mathrm{SPLg}}$ which is more precise than an estimate based on small sample increments. Wallace and Kratochvil ${ }^{[29]}$ recommended that the F-test should be applied at $90 \%$ or lower level of confidence because, when the concept is applied for sampling and a material is considered well mixed when it is not it may have severe consequences under certain circumstances. However in analytical chemistry the uncertainty is estimated at $95 \%$ level, therefore we accepted those cases as "well-mixed" where the calculated F value was smaller than the critical value at $95 \%$ level (corresponding to one sided $\mathrm{F}_{0.975,4,4}$ ). Those cases where the calculated $\mathrm{F}$ values were between the critical values at $90 \%$ and $95 \%$ levels are indicated as boarder line in the tables summarizing the results (Table 4, 5 and 6). The calculations are illustrated with an example given in Table 2A and 2B.

The $V_{\text {SPE }}$ calculated with Equation 7 includes the variability derived from the inhomogeneity of residues in the test portions, $\mathrm{V}_{\mathrm{SP}}$, and from the variability of the extraction process, $\mathrm{V}_{\mathrm{E}}$. The $\mathrm{V}_{\mathrm{A}}\left(\mathrm{S}_{\mathrm{A}}{ }^{2}\right)$ 
in Equation 1 also contains the error of extraction. In order to avoid double counting of the extraction error where the Equation 1 is used to estimate the standard uncertainty and to precisely estimate the uncertainty of sample processing the $V_{S P}$ should be quantified alone. The $V_{E}$ can be determined from the variability of recovery data obtained from the repeated analysis of the extracts of spiked analytical portions. In this case the error in spiking the test portion with the analytical standard, based on weighing the spiking solution, is negligible compared to the random variation of extraction process, so uncertainty of the results of the analysis of replicate test portions can be calculated from the variance of all measurements and the variance of the LSC measurements. Based on 96 recovery studies carried out with 20 and 200 g portions of 6 different soils, the relative standard repeatability uncertainty of the extraction, $\mathrm{CV}_{\mathrm{E}}$, was $1.05 \%$. The details of the calculation of the uncertainty of the whole determination procedure of pesticide residues in soil will be reported in a separate paper. Once the $\mathrm{V}_{\mathrm{E}}$ and $\mathrm{V}_{\mathrm{A}}$ ' are quantified the $\mathrm{V}_{\mathrm{SP}}$ can be calculated as:

$V_{S P}=V_{T}-V_{E}-V_{A}^{\prime}$

The $\sqrt{ } V_{\text {SP }}$ obtained from Equation 8 can be used to calculate $C V_{\text {SP }}$ for Equation 2 by taking into account the average recovery of the test compound.

The $\mathrm{V}_{\mathrm{SPE}}$ for $200 \mathrm{~g}$ portions was not significantly different from $\mathrm{V}_{\mathrm{A}}$ ' in many cases indicating that the sample processing error was negligible. In such cases the Ks value was calculated from the 
small test portions $(20 \mathrm{~g})$ as shown in Table 3.

In our trials 5 test portions were withdrawn, thus the degree of freedom of the estimated $\mathrm{S}_{\mathrm{SP}}$ is 4, which leads to an inevitably large variation of the estimated values obtained from the replicate experiments. Therefore the homogeneity of $\mathrm{V}_{\mathrm{SP}}$, obtained from successful trials resulted in well mixed samples $\left(F_{\text {calc }} \leq F_{0.975,4,4}\right)$, was tested with Cochran test $(\alpha=0.05)$, and the pooled variance was calculated from those values which passed the test. The typical $\mathrm{CV}_{\mathrm{SP}}$ was calculated from the pooled variance of sample processing and the mean recovery observed during sample processing. The typical sample processing constant, $\mathrm{K}_{\mathrm{SPtyp}}$, expressed in $\mathrm{kg}$ was obtained from $0.2 * \mathrm{CV}_{\mathrm{SP} 20 \mathrm{typ}}^{2}$.

From the $\mathrm{K}_{\text {SPtyp }}$ value (Equation 3) we can then calculate the uncertainty of sample processing for any test portion size, $\mathrm{m}_{\mathrm{i}}$, which is larger than the small portions used in the evaluation of the efficiency of sample processing:

$$
C V_{S P i}=\sqrt{\left(K_{S P t y p} / m_{i}\right)}
$$

The confidence intervals for the estimated typical $V_{S P}$ were calculated at $95 \%$ probability:

$$
v S_{S P}^{2} / \chi^{2}{ }_{0.025} \leq{\sigma_{S P}}^{2} \leq v S_{S P}^{2} / \chi^{2} 0.975
$$

The corresponding $\mathrm{CV}_{\mathrm{SP}}$ values were used to calculate the expectable minimum and maximum $\mathrm{K}_{\mathrm{SP}}$ 
values for each sample processing method.

\section{RESULTS AND DISCUSSION}

In our experiments we treated a relatively small portion of the soil sample in order to represent the worst scenario regarding the initial inhomogeneity of residues in the sampled soil cores (one of 30 cores contains all residues). Therefore, the laboratories applying the methods, which proved to be efficient, can assume that the contribution of sample processing to the combined uncertainty of the results will be within the estimated values.

Since the LSC measurement could be carried out with about $0.73 \%$ relative standard uncertainty, the volumetric measurements were complemented with weighing of the mass of the materials in case of all operations in order to keep the combined uncertainty as low as possible. All results were calculated on mass/mass basis.

The sample processing methods applied for various soil samples and the results of the tests are summarized in Tables 4, 5 and 6. 
The manual processing, Table 4, which is used in many laboratories, was tried first. When sandy and wet soils were processed well mixed samples could be obtained in about $76 \%$ of the tests. The Cochran homogeneity test of variances, performed with the $\mathrm{V}_{\mathrm{SP}}$ values obtained from 13 experiments resulted in well-mixed samples, indicated that the estimated variances could come from the same population as the calculated 0.292 value was between the critical values of 0.288 and 0.343 at $\alpha=0.05$ and 0.01 levels, respectively. Thus, a typical $\mathrm{K}_{\mathrm{S}}$ value of $13.3 \mathrm{~kg}$ could be calculated. However, the procedure was not well reproducible as the $\mathrm{K}_{\mathrm{S}}$ values were widely spread and occasionally the well-mixed status could not be achieved thought the procedure was applied similarly to the other cases. Further, it did not provide well-mixed sample 4 times out of 17 tests, especially in case of dry soils (U-128, V-01,V02) that contained hard clods which could not be properly disintegrated manually.

The dry soils were crushed in a mortar and ground to powder, and then processed as described under grinding method. Though powdery material was obtained the results were not reproducible. It may be attributed to the strong absorption of the spiking solution to a small portion of the dry powdery soil, and these particles could not be properly mixed with the rest of the soil sample. Therefore, we consider that the procedure for testing uncertainty of sample 
processing described in this paper is not applicable for dry soils. No published information could be found on the efficiency of this procedure, therefore it should be checked with the analysis of replicate test portions of samples taken from the fields treated with pesticides. In any case, the grinding method has an important limitation as it can only be used in those cases, where the water content of the soil is less than $5 \%$. Consequently, most of the soil samples must be dried before processing. Therefore the potential loss of analytes due to volatilization or steam distillation must be checked before this method is used. The grinding procedure was not further investigated in this study.

As the chopping and mincing in the presence of dry ice improved the efficiency of sample processing in case of plant materials ${ }^{[31]}$ and made possible to grind difficult sample matrices such as straw, stalk etc., we tested the possibility of applying dry-ice to improve the reproducibility and efficiency of processing soil samples. However, the application of dry-ice did not improve the reproducibility of processing wet soils, as the $\mathrm{K}_{\mathrm{S}}$ values were widely varying and 2 out of 5 tests did not result in well-mixed samples. As it did not show the potential for reducing the variability of residues in test portions of soils of widely varying physical conditions, further tests were not carried out. Based on the available data, the estimation of a typical $\mathrm{K}_{\mathrm{S}}$ value was not considered appropriate, and we concluded that this 
method was not applicable for the dry soils (Table 5). It should be noted, however, that where volatile compounds should be analyzed in wet soil, the use of dry-ice during sample processing may provide the best option.

Adding water to the sample (Table 6) to facilitate homogenization is used for plant samples for pesticide residue analysis ${ }^{[30]}$ as well as for obtaining well-mixed materials for mycotoxin analysis with slurry technique. Further, water is frequently added to test portions of soil before extraction ${ }^{[35,36]}$. Therefore, we investigated how the addition of water would improve the homogenization process. This method proved to be very efficient for all types of soils, and it was the most reproducible among the procedures tested. The $K_{S}$ value was almost 20 times smaller than that obtained for manual processing resulting in a $\mathrm{CV}_{\mathrm{SP}}$ of $6 \%$ for $20 \mathrm{~g}$ test portion, and $7.75 \%$ at the upper $95 \%$ confidence limit. Figure 2 shows the typical $\mathrm{K}_{\mathrm{S}}$ values with their confidence intervals for manual processing and blending in the presence of water. It should be noted that values are only postulated below $20 \mathrm{~g}$ test portion, as the procedures were not tested with smaller test portions.

\section{Internal Quality Control}


Since the efficiency of sample processing can be significantly influenced by the actual physical conditions of the soil samples, it is not sufficient to test its efficiency once at the time of method validation, but is should be checked regularly during the application of the method.

During the use of the method, as part of the performance verification, the $\mathrm{CV}_{\mathrm{Lab}}$ can be conveniently determined from the residues measured in duplicate portions of samples containing field-incurred residues. If the relative difference of the residues measured in replicate portions is $\mathrm{R}_{\Delta \mathrm{i}}=2\left(\mathrm{R}_{\mathrm{i} 1} / \mathrm{R}_{\mathrm{i} 2}\right) /\left(\mathrm{R}_{\mathrm{i} 1}+\mathrm{R}_{\mathrm{i} 2}\right)$, then $C V_{L a b}=\sqrt{\frac{\sum_{i=1}^{n} R_{\Delta i}^{2}}{2 n}}$

Assuming that only random error affects the duplicate measurements, the average of random errors in many measurements must be zero. Thus the degree of freedom is equal to $\mathrm{n}$, the number of measurement pairs. ${ }^{[23]} \mathrm{The} \mathrm{CV}_{\mathrm{A}}$ is determined from the results of recovery studies performed with spiked analytical portions. If required, the actual $\mathrm{CV}_{\mathrm{Sp}}$ can be determined from $\mathrm{CV}_{\text {Lab }}$ and $\mathrm{CV}_{\mathrm{A}}$ after the rearrangement of Equation 2.

Once the typical $\mathrm{CV}_{\mathrm{Lab}}$ is established based on method validation and performance verification tests, the daily performance of the method can be tested by comparing the difference of results of replicate test portions to the critical difference calculated from the typical $\mathrm{CV}_{\text {Lab }}$ value taking into 
account its degree of freedom which will effect the f value.

Where the

$\left|R_{1}-R_{2}\right| \leq f 0.5\left(R_{1}+R_{2}\right) C V_{L a b}$

it can be declared that the used method performed as expected and the estimated combined uncertainty is valid for the results obtained. Where the estimation of the $\mathrm{CV}_{\mathrm{Lab}}$ is based on large number of measurements ( $>20$ ), 2.8 can be used for $\mathrm{f}$ in case of duplicate measurements. ${ }^{[37]}$ For smaller degree of freedom or larger number of replicate measurements the value for $f$ can be taken from statistical tables for Studentised extreme range. ${ }^{[38]}$

\section{Optimization of the Analytical Procedure}

The information on the relative contribution of various components to the combined uncertainty may be very useful in optimizing the experimental design for a study or an analytical procedure. The number and size of samples to be taken, the mass of analytical portion and the number of replicate samples to be analysed can be better decided if the uncertainties of the procedures are taken into account. Attempting to reduce the uncertainty of individual steps may not be worth beyond a certain level, as the overall uncertainty will not be improved significantly. 
Table 7 shows some example for the relative contribution of sampling, sample processing and analysis to the combined relative standard uncertainty of the results. It can be seen that any of the steps can be a major contributor to the combined uncertainty. The magnitude of the contribution of sample processing to the combined uncertainty depends on its ratio to the uncertainty of sampling and analysis. Assuming a $25 \%$ error of sampling, $15 \%$ and $25 \%$ error of analysis, the contribution of sample processing becomes practically insignificant at or below $8 \%$ and $10 \%$, respectively. The mass of test portion can be selected accordingly taking into account the sub-sampling constant, $\mathrm{K}_{\mathrm{SP}}$, of the procedure.

\section{CONCLUSIONS}

The application of the principles of sampling constant, $K_{S}$, for characterizing the efficiency of a sample processing method has a definite advantage over testing the homogeneity of samples with ANOVA calculation, as the expectable sample processing uncertainty can be calculated from it for any test portion size larger than the small portion used for its determination.

The use of ${ }^{14} \mathrm{C}$-labeled atrazine as a model substance was very advantageous, since we could precisely (with a typical relative standard deviation $\leq 1-1.5 \%$ ) and quickly (within 15 minutes) determine the analyte directly in the extract and eliminate the effects of the rest of the analytical 
procedure, which greatly improved the precision of the final results. Naturally, the elaborated methodology can also be applied without labeled compound, but its implementation takes longer and the estimated $\mathrm{K}_{\mathrm{S}}$ is less precise.

Even if statistically well-mixed samples were obtained with manual mixing or grinding the procedures were not well reproducible, and they could only be used for a limited range of samples.

The processing in the presence of water can be carried out with the usually available equipment of pesticide residue laboratories and it is considered suitable for general use in multi residue analysis. The results obtained for different type of soils did not differ significantly, thus the estimated typical $\mathrm{K}_{\mathrm{S}}$ value can be used for most frequently occurring soils.

The sample processing uncertainty in well-mixed soil samples is inversely proportional to the mass of the test portion. For $20 \mathrm{~g}$ test portion typically $6 \%$ relative uncertainty may be expected with wet processing. If the well-mixed status can be achieved at all at 2-5 g test portion level the sample processing uncertainty would be 19-12\%. This relatively large uncertainty should be taken into account where small test portions are extracted e.g. accelerated solvent extraction or 
supercritical fluid extraction are used. The variability with other processing methods may be much higher depending on the type of soil and physical condition of the sample. Therefore, the efficiency of sample processing should be checked initially as part of the method validation and regularly during the use of the method with the re-analysis of a second test portion withdrawn from randomLy selected samples.

The efficiency of sample processing is independent from the pesticide residues being present in the sample. Therefore once the efficiency of sample processing is determined during method validation and verified by internal quality control procedures, the results obtained are valid for all pesticide residues except highly volatile and labile compounds which can evaporate or degrade during the process at various extent depending on the conditions of the laboratory environment.

Thorough testing of the efficiency of sample processing procedure requires an extensive study, but the information obtained on the uncertainty of a given procedure can be used in future for the estimation of the combined uncertainty of the results. Therefore, it seems more practical and economical to test the efficiency of the physical sample processing methods applied in a laboratory with stable compounds and establish its standard uncertainty, and then apply the 
standardized procedures, described in detail in SOPs, for the validation of analytical methods for different pesticide residues. The method validation should naturally include testing the stability of analyte and determine its portion survived after sample processing together with its uncertainty. The average loss of analyte during sample processing can be combined with the average procedural recovery to obtain the systematic error of the determination. Similarly the combined uncertainties of these two steps should be calculated and taken into account in the estimation of the uncertainty of the results. ${ }^{[39]}$

\section{ACKNOWLEDGMENT}

The ${ }^{14} \mathrm{C}$-labeled atrazine was provided by Syngenta Co. The Soil testing Laboratory of PPSCS of Fejér County, Hungary, performed the soil analysis. Mr. N.M. Rathor assisted in the LSC measurements. Their contribution and cooperation are sincerely appreciated.

\section{REFERENCES}

1. Saim, N.; Dean, M.P.; Abdullah M.P.; Zakaria, Z. Extraction of polycyclic aromatic hydrocarbons from contaminated soil using Soxhlet extraction, pressurised and atmospheric 
microwave-assisted extraction, supercritical fluid extraction and accelerated solvent extraction. J.

Chromatogr. A. 1997, 791, 361-366.

2. Molins, C.; Hogendororn, D.E.; Heusinkveld, Bauman R.A. Determination of linuron and related compounds in soil by microwave-assisted solvent extraction and reversed-phase liquid chromatography with UV detection. J. Chromatogr. A. 2000, 869, 487-496.

3. EPA Method 3545, Pressurised Fluid Extraction, Test Methods for Evaluating Solid Waste, $3^{\text {rd }}$ ed. Update III. EPA SW-846; USGPO, Washington, DC, 1995.

4. Bautz H.; Polzer J.; Stieglitz L. Comparison of pressurised liquid extraction with Soxhlet extraction for the analysis of polychlorinated dibenzo-p-dioxins and dibenzofurans from fly ash and environmental matrices. J. Chromatogr, A. 1998, 815, 231-241.

5. Chee, K.K.; Wong, M.K.; Lee, H.K. Optimization of microwave-assisted solvent extraction of polycyclic aromatic hydrocarbons in marine sediments using a microwave extraction system with high-performance liquid chromatography-fluorescence detection and gaschromatography-mass spectometry. J. Chromatogr. A. 1996, 723, 259-271.

6. Vazquez, M.J.; Carro, A.M.; Lorenzo, R.A.; Cela, R. Optimization of methylmercury microwave-assisted extraction from aquatic sediments. Anal Chem. 1997, 69, 221-228. 
7. Conte, E.; Milani, R.; Morali, G.; Abballe, F. Comparison between accelerated solvent extraction and traditional extraction methods for the analysis of the herbicide diflufenican in soil. J.

Chromatogr. A. 1997, 765, 12-125.

8. Vinas, P.; Campillo, N.; López-Garcia, I.; Aguinaga, N.; Hernández-Cordoba, M. Capillary gas chromatography with atomic emission detection for pesticide analysis in soil samples. J. Agric. Food Chem. 2003, 51, 3704-3708.

9. Wells, D.E.; Hess, P. Separation, clean-up and recoveries of persistent trace organic contaminants from soils, sediment and biological matrices. In Sample handling and Trace Analysis of Pollutants: techniques, Applications and Quality Assurance, Ed. D. Barcelló, Elsevier Science, B.V., 1999; 73-113.

10. Ambrus, A.; Lantos, J.; Visi, E.; Csatlós. I.; Sárvári, L. Determination of pesticide residues in samples of plant origin, soil and water, I. Extraction and cleanup. J. AOAC Int. 1981, 64, $733-742$

11. Taylor, A. W.; Caro, J.H.; Freeman, H.P; Turner, B. Sampling and variance in measurement of trifluralin disappearance from soil. Proc. Am. Chem. Soc. 1985, 25-35.

12. ISO/CD 11464 Soil quality - Pre-treatment of samples for physico-chemical analysis $1^{\text {st }}$ rev. ISO Geneva, 2002. 
13. Aharonson, N. Potential contamination of ground water by pesticides. Pure \& Appl. Chem. 1987, $59(10), 1419-1446$.

14. Ritter, W.F.; Johnson, H.P.; Lovely, W.G.; Malnau, M. Atrazine, Propachlor, and Diazinon residues on small agricultural watersheds runoff losses, persistence, and movement. Environ. Sci. Technol. 1974, 8, 39-42.

15. Wauchope, R.D. The pesticide content of surface water draining from agricultural fields--A Review. J. Environ. Qual. 1978, 38, 459-472.

16. R.A. Leonard. Movement of pesticides into surface water. In Pesticides in the Soil Environment: Processes, Impacts and Modeling. 1st Ed.; ed. H.H. Cheng; SSA Book Ser; Soil Science Society of America, Madison, W1, 1990; No. 2, p. 303-350.

17. Ferenczi, J.; Ambrus, A.; Wauchope, R.D.; Summer, H.R. Persistence and runoff losses of 3 herbicides and chlorpyrifos from a corn field in the lake Balaton watershed of Hungary. J.

Environ. Sci. Health. 2002, B37, 211-224.

18. Unsworth, J.B., Wauchope, R.D.; Klein, A.W., Dorn, E., Zeeh, B.; Yeh, S.M.; Akerblom, M.; Racke, K. D.; Rubin, B. Significance of the long range transport of pesticides in the atmosphere. Pure Appl. Chem., 1999, 71 (7), 1359-1383. 
19. Rajagopal, B.S.; Brahmaprakash, G.P.; Reddy, B.R.; Singh, U.D.; Sehunathan N. Effect and persisitence of selected carbamate insecticides in soil. Eds. Gunther F.A.; Gunther, J.D. Residue Reviews, 1984, 93, 2-198.

20. Wauchope, R.D.; Yeh, S.; Linders, Jan B.H.J.; Kloskowski, R.; Tanaka, K.; Rubin, B.; Katamaya, A.; Kördel, W.; Gerstl, Z.; Lane, M.; Unsworth, J. B. Pesticide soil sorption parameters: theory, measurement, uses, limitations and reliability. Pest. Manag. Sci. 2002, 58, 419-445.

21. Khan S.U. Bound residues in soil and plants.Eds. Gunther, F.A.; Gunther, J.D. Residue Reviews, $1982,84,1-25$.

22. Roberts, T.R.Non-extractable pesticide residues in soils and plants. Pure \&Appl. Chem. 1984, $56,945-956$.

23. Youden, W.J.; Steiner, E.H. Statistical manual of AOAC, AOAC, 1975.

24. Hill A.R.C.; Reynolds, S.L. Guidelines for in-house validation of analytical methods for pesticide residues in food and animal feeds. Analyst. 1999, 124, 953-958.

25. Report of the $35^{\text {th }}$ Session of Codex Committee on Pesticide Residues, Codex Alimentarious 2003, URL: http://ftp.fao.org/codex/alinorm03/A10324Ae.pdf.

26. Quantifying Uncertainty in Analytical Measurements. $2^{\text {nd }}$ Ed., EURACHEM, 1999, URL: http://www.measurementuncertainty.org 
27. Bettencourt da Silva, R.J.N.; Lino, M.J.; Santos, J.R. Evaluation of the sampling procedure adopted by the EU pesticide meonitoring programme to assess consumer exposure to high acoute toxicity pesticides - methamidophos in sweet pepper. Accred Qual Assur. 2002, 7, 195-201.

28. Lyn, J.A.; Ramsey, M.H.; Fussel, R.; Wood, J.R. Measurement uncertainty from physical sample preparation: estimation including systematic error. Analyst. 2003, 128, 1391-1398.

29. Wallace, D.; Kratochvil, B. Visman equation in the design of sampling plans for chemical anlysis of segregated bulk materials. Anal. Chem. 1987, 59, 226-232.

30. Ambrus, A.; Solymosné, M.E.; Korsós, I. Estimation of unecertainty of sample preparation for the analysis of pesticide residues. J. Environ. Sci. Health. 1996, B31, 443-450.

31. Maestroni, B.; Ghods, A.; El-Bidaoui, M.; Rathor, N.; Ton. T.; Ambrus A. Testing the efficiency and uncertainty of sample processing using ${ }^{14} \mathrm{C}$ labelled Chlorpyrifos, Part II. In Principles of Method Validation, Eds. Fajgelj, A.; Ambrus, A.; Royal Society of Chemistry: Cambridge UK, 2000; 59-74.

32. Hill, A.R.C.; Harris, C.A.; Warburton, A.G. Effects of Sample Processing on Pesticide Residues in Fruit and Vegetables. In Principles of Method Validation, Eds. Fajgelj, A.; Ambrus, A.; Royal Society of Chemistry: Cambridge UK, 2000; 41-48. 
33. El-Bidaoui, M.; Jarju, O.P.; Maestroni, B.; Phakaeiw, Y.; Ambrus, A. Testing the effect of sample processing and storage on stability of residues. In Principles of Method Validation, Eds. Fajgelj, A.; Ambrus, A.; Royal Society of Chemistry: Cambridge UK, 2000; 75-88.

34. Fussel, R.J.; Jackson, A.K.; Reynolds, S.L.; Wilson, M.F. Assessment of the stability of pesticides during cryogenic sample processing. 1. Apples. J. Agric.Food Chem. 2002, 50, $441-448$.

35. Jarzick, H.J.; Amitrole, M.E. Manual of Pesticide residue Analysis, Eds. Hans-Pieter Their, Jochen Kirchoff Working Group "Analysis”, Deutsche Forschungsgemeinschaft, VCH, Vol. 2., $51-54$

36. Taylor, A.W.; Freeman, H.P.; Edwards, W.M. Sample variability and the measurement of dieldrin content of a soil in the field. J.Agr. Food Chem. 1971, 19, 832-836.

37. ISO-5725-6. Accuracy (trueness and precision) of measurement methods and results - Part 6 Use in practice of accuracy values, 1994.

38. C. Lentner, Geigy Scientific Tables, 8th revised Ed., Vol. 2. Ciba-Geigy Ltd, Basle, 1982, p. 58. 39. Thompson, M.; Ellison, S.; Fajgelj, A.; Willets, P.; Wood, R. Harmonised guidelines for the use of recovery information in analytical measurement. Pure and Appl Chem. 1999, 71, 337-348. 


\section{FIGURE CAPTIONS}

Figure 1. Scheme of sub-sample divider.

Figure 2. Relative uncertainty $(\mathrm{CV})$ of processing test portions of different size manually $(\mathrm{M})$ and in the presence of water (W). 
Fig.1

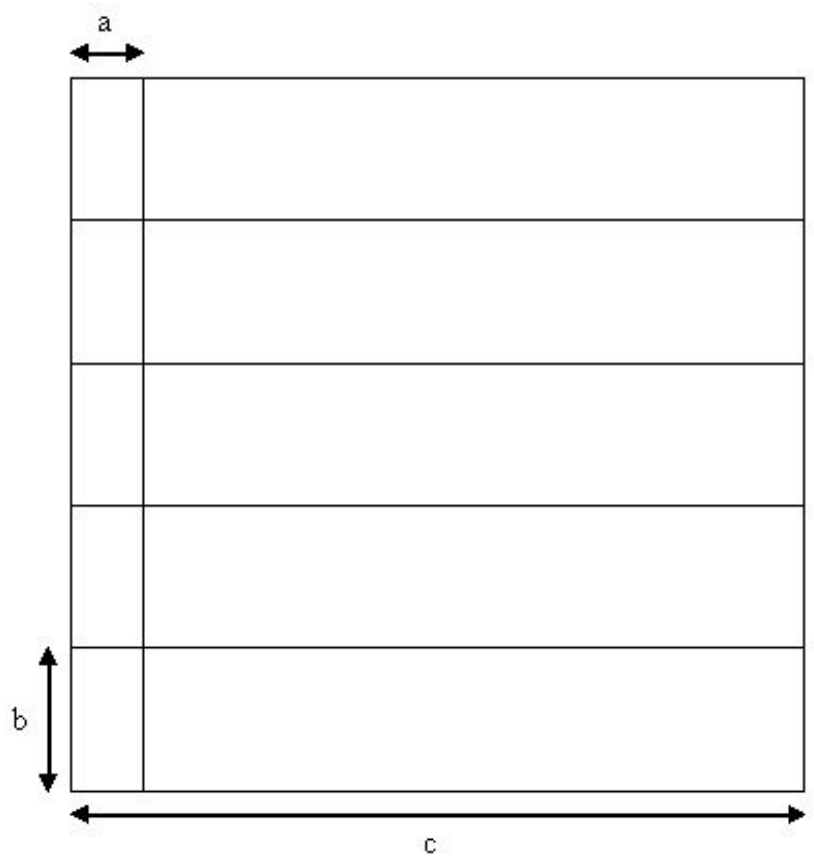

$(\mathrm{a}=4 \mathrm{~cm} ; \mathrm{b}=8 \mathrm{~cm} ; \mathrm{c}=40 \mathrm{~cm} ;$ depth $=2 \mathrm{~cm})$ 
Fig. 2

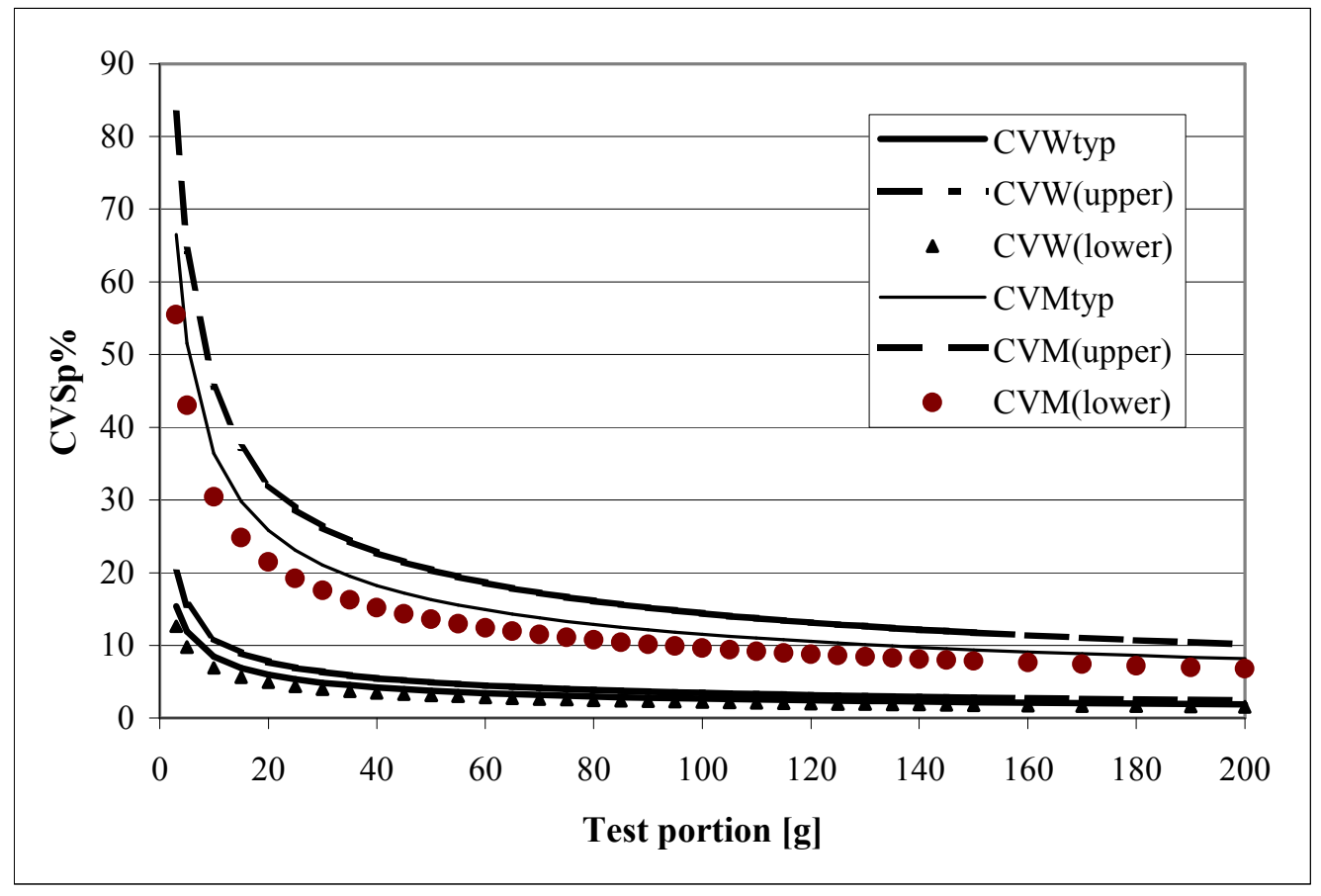


Table 1. Properties of soils tested.

\begin{tabular}{|c|c|c|c|c|c|c|c|c|c|}
\hline \multirow{4}{*}{$\begin{array}{c}\text { Lab. Code } \\
\text { of the } \\
\text { sample }\end{array}$} & \multirow{4}{*}{$\begin{array}{c}\text { Organic } \\
\text { matter }(\%)\end{array}$} & \multirow{4}{*}{$\mathrm{pH}(\mathrm{H} 2 \mathrm{O})$} & \multicolumn{7}{|c|}{ Particle size $(\mathrm{mm})$} \\
\hline & & & \multicolumn{3}{|c|}{ Sand $(\%)$} & \multicolumn{3}{|c|}{ Silt (\%) } & \multirow{3}{*}{$\frac{\text { Clay }(\%)}{>0.002}$} \\
\hline & & & $>0.25$ & $0.25-$ & $0.05-$ & $0.02-$ & $0.01-$ & $0.005-$ & \\
\hline & & & & 0.05 & 0.02 & 0.01 & 0.005 & 0.002 & \\
\hline V01 & 2.15 & 6.74 & 18.9 & 29.1 & 10.2 & 4.6 & 12.4 & 6.1 & 18.8 \\
\hline U-128 & 3.43 & 6.55 & 17.6 & 24.0 & 11.8 & 5.1 & 9.0 & 2.5 & 29.9 \\
\hline $\mathrm{W}-33$ & 2.56 & 7.69 & 4.2 & 26.5 & 12.3 & 8.8 & 9.7 & 9.0 & 29.4 \\
\hline V03 & 2.46 & 6.43 & 15.0 & 21.1 & 9.9 & 7.5 & 8.7 & 5.1 & 32.6 \\
\hline Y-97 & 3.14 & 6.41 & 3.0 & 7.2 & 23.6 & 17.4 & 18.5 & 5.7 & 24.6 \\
\hline U-129 & 2.09 & 6.37 & 2.2 & 16.1 & 18.8 & 17.0 & 12.8 & 5.2 & 28.0 \\
\hline$X-65$ & 2.40 & 6.80 & 10.4 & 12.4 & 13.2 & 11.1 & 12.1 & 3.3 & 37.5 \\
\hline V02 & 1.89 & 6.34 & 1.4 & 9.8 & 15.1 & 10.3 & 11.4 & 5.0 & 46.9 \\
\hline
\end{tabular}


Table 2A. Measured activities in the extract (processing of Y-97 sample with water).

\begin{tabular}{|c|c|c|c|c|c|c|c|c|}
\hline \multirow{2}{*}{$\begin{array}{c}200 \text { g Analytical } \\
\text { portion ID }\end{array}$} & \multicolumn{4}{|c|}{$A^{a}$} & \multirow{2}{*}{$\mathrm{A}_{\mathrm{AVE}}$} & \multirow{2}{*}{$\mathrm{V}_{\mathrm{A}}^{\mathrm{b}}$} & \multirow{2}{*}{$\mathrm{CV}$} & \multirow{2}{*}{$\mathrm{R}_{\mathrm{AVE}} \%{ }^{\mathrm{c}}$} \\
\hline & $\mathrm{i}$ & $\mathrm{A}_{1 \mathrm{i}}$ & $\mathrm{A}_{2 \mathrm{i}}$ & $\mathrm{A}_{3 \mathrm{i}}$ & & & & \\
\hline Y-97/W/1/200/1 & 1 & 2026.018 & 2026.098 & 2024.533 & 2025.316 & 1.226 & 0.001 & 86.567 \\
\hline Y-97/W/1/200/2 & 2 & 2081.419 & 2056.415 & 1948.574 & 2028.803 & 4983.765 & 0.035 & 86.716 \\
\hline Y-97/W/1/200/3 & 3 & 2034.587 & 1784.384 & 2087.927 & 1968.966 & 26264.148 & 0.082 & 84.158 \\
\hline Y-97/W/1/200/4 & 4 & 2068.978 & 2077.636 & 2063.248 & 2069.954 & 52.467 & 0.003 & 88.475 \\
\hline Y-97/W/1/200/5 & 5 & 2136.330 & 2097.094 & 2130.784 & 2121.403 & 450.892 & 0.010 & 90.674 \\
\hline Average & & & & & $\begin{array}{c}\mathrm{A}_{\mathrm{AVE} 200} *= \\
2042.888\end{array}$ & $\begin{array}{c}\mathrm{V}_{\mathrm{A} 200}= \\
6350.49950\end{array}$ & & \\
\hline \multirow{2}{*}{$\begin{array}{l}20 \mathrm{~g} \text { Analytical } \\
\text { portion ID }\end{array}$} & \multicolumn{4}{|c|}{$\mathrm{A}^{\mathrm{a}}$} & \multirow{2}{*}{$\mathrm{A}_{\mathrm{AVE}}$} & \multirow{2}{*}{$\mathrm{V}_{\mathrm{A}}^{\mathrm{b}}$} & \multirow{2}{*}{$\mathrm{CV}$} & \multirow{2}{*}{$\mathrm{R}_{\mathrm{AVE}} \%^{\mathrm{c}}$} \\
\hline & $\mathrm{i}$ & $\mathrm{A}_{1 \mathrm{i}}$ & $\mathrm{A}_{2 \mathrm{i}}$ & $\mathrm{A}_{3 \mathrm{i}}$ & & & & \\
\hline $\mathrm{Y}-97 / \mathrm{W} / 1 / 20 / 1$ & 1 & 2152.262 & 2126.830 & 2126.241 & 2135.111 & 220.701 & 0.007 & 91.260 \\
\hline $\mathrm{Y}-97 / \mathrm{W} / 1 / 20 / 2$ & 2 & 2081.028 & 2117.560 & 2266.916 & 2155.168 & 9699.424 & 0.046 & 92.117 \\
\hline $\mathrm{Y}-97 / \mathrm{W} / 1 / 20 / 3$ & 3 & 2132.464 & 2443.514 & 2089.768 & 2221.915 & 37285.285 & 0.087 & 94.970 \\
\hline $\mathrm{Y}-97 / \mathrm{W} / 1 / 20 / 4$ & 4 & 2068.200 & 2056.802 & 2026.076 & 2050.359 & 474.732 & 0.011 & 87.637 \\
\hline $\mathrm{Y}-97 / \mathrm{W} / 1 / 20 / 5$ & 5 & 2064.322 & 2078.472 & 2085.098 & 2075.964 & 112.621 & 0.005 & 88.731 \\
\hline Average & & & & & $\begin{array}{l}\mathrm{A}_{\mathrm{AVE} 20} *= \\
2127.703\end{array}$ & $\begin{array}{c}\mathrm{V}_{\mathrm{A} 20}= \\
9558.553\end{array}$ & & \\
\hline
\end{tabular}

${ }^{a}$ Measured activities in dpm/g sample. ${ }^{\mathrm{b}}$ Variance of analysis. ${ }^{\mathrm{c}}$ Average recovery in \%.* Average of the five $\mathrm{A}_{\mathrm{AVE}}$ 
Table 2B. An example to illustrate the calculation of $\mathrm{F}_{\text {calc }}$ *

\begin{tabular}{|c|c|c|c|}
\hline & Calculation steps & $\begin{array}{l}\text { Calc. values for the } 200 \mathrm{~g} \\
\text { portion }\end{array}$ & $\begin{array}{l}\text { Calc. values for the } 20 \mathrm{~g} \\
\text { portion }\end{array}$ \\
\hline 1 & $\mathrm{CV}_{\mathrm{A}}, \mathrm{a}=\sqrt{ } \mathrm{V}_{\mathrm{A}} / \mathrm{A}_{\mathrm{AVE}} *$ & $\mathrm{CV}_{\mathrm{A} 200}{ }^{\prime}=0.03901$ & $\mathrm{CV}_{\mathrm{A} 20}{ }^{\prime}=0.04595$ \\
\hline 2 & $\begin{array}{l}\mathrm{V}_{\mathrm{T}}^{\mathrm{b}} \text { (variance of } \mathrm{A}_{11}-\mathrm{A}_{35} \\
\text { for both test portions) }\end{array}$ & $\mathrm{V}_{\mathrm{T} 200}=7291.86$ & $\mathrm{~V}_{\mathrm{T} 20}=10758.42$ \\
\hline 3 & $\mathrm{~F}_{\text {calc }}$ & $\begin{array}{l}\mathrm{F}_{\text {calc200 }}=\mathrm{V}_{\mathrm{T} 200} / \mathrm{V}_{\mathrm{A} 200} \\
=1.148\end{array}$ & $\begin{array}{l}\mathrm{F}_{\text {calc20 }}=\mathrm{V}_{\mathrm{T} 20} / \mathrm{V}_{\mathrm{A} 20} \\
=1.13\end{array}$ \\
\hline 4 & $\mathrm{~V}_{\mathrm{SPE}}{ }^{\mathrm{c}}=\mathrm{V}_{\mathrm{T}}-\mathrm{V}_{\mathrm{A}}$ & $\mathrm{V}_{\text {SPE200 }}=941.36$ & $\mathrm{~V}_{\mathrm{SPE} 20}=1199.87$ \\
\hline 5 & $\mathrm{~F}_{\mathrm{calc}} *$ & \multicolumn{2}{|c|}{$\begin{array}{l}\text { if } \mathrm{V}_{\text {SPE200 }} \times 10>\mathrm{V}_{\text {SPE20 }} ; \mathrm{F}_{\text {calc }}{ }^{\prime}=\mathrm{V}_{\text {SPE200 }} \times 10 / \mathrm{V}_{\text {SPE20 }}= \\
7.845 \\
\text { if } \mathrm{V}_{\text {SPE200 }} \times 10<\mathrm{V}_{\text {SPE20 }}, \mathrm{F}_{\text {calc }}{ }^{\prime}=\mathrm{V}_{\text {SPE20 }} / \mathrm{V}_{\text {SPE200 }} \times 10\end{array}$} \\
\hline 6 & Conclusion & \multicolumn{2}{|c|}{$\begin{array}{l}F_{\text {crit }(0.975,4,4)}=9.605 ; F_{\text {crit }(0.95,4,4)}=6.388 \\
\text { if } F_{\text {calc }} *>F_{\text {crit }(0.95,4,4)}=\text { sample is not well mixed } \\
\text { if } F_{\text {calc }} *<F_{\text {crit }(0.95,4,4)}=\text { sample is well mixed }\end{array}$} \\
\hline
\end{tabular}

${ }^{a}$ Uncertainty of analysis. ${ }^{\mathrm{b}}$ Variance of residues measured in the test portions. ${ }^{\mathrm{c}}$ Includes the variability derived from the inhomogeneity of residues in the test portions, $\mathrm{V}_{\mathrm{SP}}$, and from the variability of the extraction process, $\mathrm{V}_{\mathrm{E}}$. 
Table 3. Illustration of the calculation of the $K_{S}$ value for processing of Y-97 sample with water.

\begin{tabular}{ll}
\hline & \multicolumn{1}{c}{ Calculation steps } \\
\hline 1 & $\mathrm{CV}_{\mathrm{SPE} 200}=1.50 \%, \mathrm{CV}_{\mathrm{E}}=1.05 \%$ \\
2 & $\mathrm{~K}_{\mathrm{SPE}}=\mathrm{mL}_{\mathrm{g}} \times \mathrm{CV}_{\mathrm{SPE} 20}{ }^{2}=0.2 \times 1.50^{2}=0.451$ \\
3 & $\mathrm{CV}_{\mathrm{SPE} 20}=\sqrt{ }\left(\mathrm{K}_{\mathrm{SPE}} / \mathrm{m}_{\mathrm{Sm}}\right)=\sqrt{ }(0.451 / 0.02)=4.75 \%$ \\
4 & $\mathrm{~F}_{\text {calc }}=\mathrm{CV}_{\mathrm{SPE} 20} / \mathrm{CV}_{\mathrm{E}}^{2}=4.75^{2} / 1.05^{2}=20.45$ \\
5 & $\mathrm{~F}_{\text {calc }}>\mathrm{F}_{0.05,4,95}=2.47$ \\
6 & $\mathrm{CV}_{\mathrm{SP} 20}=\sqrt{ }\left(\mathrm{CV}_{\mathrm{SPE} 20}{ }^{2}-\mathrm{CV}_{\mathrm{E}}^{2}\right)=\sqrt{ }\left(4.75^{2}-1.05^{2}\right)=4.63 \%$ \\
7 & $\mathrm{~K}_{\mathrm{Sp}}=\mathrm{m}_{\mathrm{Sm}} \times \mathrm{CV}_{\mathrm{SP} 20}{ }^{2}=0.02 \times 4.63^{2}=0.429$ \\
8 & Note the difference: $\mathrm{K}_{\mathrm{SPE}}>\mathrm{K}_{\mathrm{SP}}$ \\
\hline
\end{tabular}

${ }^{a}$ For improving its appearance, the table contains rounded figures, but the calculations were performed with Excel with the original numbers. 
Table 4. The estimated uncertainty of processing of various soil samples - Manual mixing.

\begin{tabular}{|c|c|c|c|c|}
\hline Soil & $\mathrm{F}_{\text {calc }}{ }^{\mathrm{a}}$ & Homogeneity $^{b}$ & $\mathrm{~K}_{\mathrm{S}}$ & $\mathrm{CV}_{\mathrm{SP} 20 \mathrm{~g}} \%$ \\
\hline \multirow{3}{*}{ Y-97 } & 1.521 & WM & 0.83 & 6.4 \\
\hline & 2.486 & WM & 5.61 & 16.8 \\
\hline & 79.684 & NWM & - & - \\
\hline \multirow{4}{*}{$X-65$} & 1.889 & $\mathrm{WM}^{\mathrm{c}}$ & 0.22 & 3.3 \\
\hline & 1.321 & WM & 3.05 & 12.3 \\
\hline & 1.449 & WM & 26.5 & 36.4 \\
\hline & 5.007 & WM & 50.4 & 50.2 \\
\hline \multirow{4}{*}{ W-33 } & 2.615 & WM & 1.07 & 7.3 \\
\hline & 2.125 & WM & 23.28 & 34.1 \\
\hline & 6.809 & WM & 1.64 & 9.1 \\
\hline & 3.970 & WM & 6.38 & 17.9 \\
\hline \multirow{2}{*}{ V01 } & 21.967 & NWM & - & - \\
\hline & 2.742 & WM & 49.7 & 49.8 \\
\hline \multirow{2}{*}{ V02 } & 8.687 & WM & 3.8 & 13.8 \\
\hline & 16.496 & NWM & - & - \\
\hline U-128 & 15.395 & NWM & - & - \\
\hline U-129 & 3.527 & WM & 3.3 & 3.9 \\
\hline No of trials & 17 & & & \\
\hline $\mathbf{K}_{\text {Styp }}$ & $13.3_{(13)}{ }^{d}$ & & & \\
\hline $\mathrm{K}_{\text {Smin }}$ & 9.2 & & & \\
\hline $\mathrm{K}_{\text {Smax }}$ & 20.7 & & & \\
\hline
\end{tabular}

${ }^{a} \mathrm{~F}_{\text {crit }(0.975,4,4)}=9.605 ; \mathrm{F}_{\text {crit }(0.95,4,4)}=6.388$, Italic values: border line $\left(\mathrm{F}_{\text {crit }(0.95,4,4)}<\mathrm{F}_{\text {calc }}<\mathrm{F}_{\text {crit }}(0.975\right.$, 4,4)). Bold values: $F_{\text {calc }}>F_{\text {crit }(0.95,4,4)}{ }^{\mathrm{b}} \mathrm{WM}$ : well mixed; NWM: not well mixed. ${ }^{\mathrm{c}}$ The $\mathrm{V}_{\mathrm{T}} \sim \mathrm{V}_{\mathrm{A}}$ for both test portion size. $\mathrm{K}_{\mathrm{S}}$ was calculated from the $\mathrm{CV}_{\mathrm{SPE} 200 \mathrm{~g}}=1.1 \%\left(\mathrm{CV}_{\mathrm{SPE} 20 \mathrm{~g}}=2.4 \%\right)$. ${ }^{\mathrm{d}}$ Not well mixed samples (bold values) were left out of the calculation. 
Table 5. The estimated uncertainty of processing of various soil samples in the presence of dry ice.

\begin{tabular}{|c|c|c|c|c|}
\hline Soil & $\mathrm{F}_{\text {calc }}{ }^{\mathrm{a}}$ & Homogeneity $^{b}$ & $\mathrm{~K}_{\mathrm{S}}$ & $\mathrm{CV}_{\mathrm{SP} 20 \mathrm{~g}} \%$ \\
\hline Y-97 & 2.234 & WM & 13 & 26 \\
\hline$X-65$ & 1.497 & WM & 1.15 & 7.6 \\
\hline W-33 & 1.497 & WM & 25 & 35 \\
\hline V01 & - & - & - & - \\
\hline V02 & - & - & - & - \\
\hline U-128 & 29.813 & NWM & - & - \\
\hline U-129 & 126.427 & NWM & - & - \\
\hline No of trials & 5 & & & \\
\hline $\mathbf{K}_{\text {Styp }}$ & $x x^{c}$ & & & \\
\hline $\mathrm{K}_{\text {Smin }}$ & - & & & \\
\hline $\mathrm{K}_{\mathrm{Smax}}$ & - & & & \\
\hline
\end{tabular}

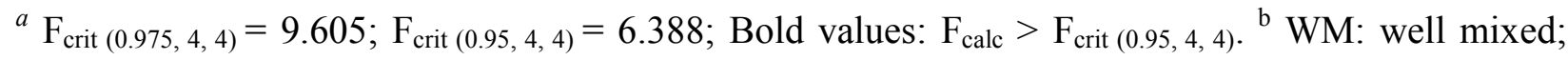
NWM: not well mixed. ${ }^{\mathrm{c}}$ The calculated average value is 13.1 , but it cannot be considered as typical value because from the 5 tests 2 gave NWM results, and the $K_{S}$ ranged between 1.15 and 25 in the remaining three tests. 
Table 6. The estimated uncertainty of processing of various soil samples with additional water.

\begin{tabular}{|c|c|c|c|c|c|}
\hline Soil & $\mathrm{F}_{\text {calc }}{ }^{\mathrm{a}}$ & Homogeneity & $\mathrm{CV}_{\text {SPE } 20 \mathrm{~g}} \%$ & $\mathrm{CV}_{\mathrm{SP} 20 \mathrm{~g}} \%$ & $\mathrm{~K}_{\mathrm{S}}$ \\
\hline & 30.586 & $\mathrm{WM}^{\mathrm{e}}$ & 8.12 & 8.05 & 1.30 \\
\hline & 1.460 & WM & 3.79 & 3.64 & 0.27 \\
\hline \multirow[t]{4}{*}{$\mathrm{U}-128^{\mathrm{g}}$} & 2.007 & WM & 1.73 & 1.37 & 0.04 \\
\hline & 5.981 & WM & 1.85 & 1.52 & 0.05 \\
\hline & 5.693 & WM & 1.44 & 0.98 & 0.02 \\
\hline & 25.702 & NWM & - & - & - \\
\hline \multirow[t]{2}{*}{$\mathrm{U}-129^{\mathrm{h}}$} & 3.494 & WM & 15.03 & 15.00 & 4.50 \\
\hline & 57.487 & $\mathrm{WM}^{\mathrm{f}}$ & 1.70 & 1.34 & 0.04 \\
\hline Y-97 & 7.845 & $\mathrm{WM}^{\mathrm{c}}$ & 4.75 & 4.63 & 0.43 \\
\hline$X-65$ & 5.497 & WM & 2.10 & 1.82 & 0.07 \\
\hline W-33 & 226.450 & $\mathrm{WM}^{\mathrm{d}}$ & 4.62 & 4.49 & 0.40 \\
\hline No of trials & 11 & & & & \\
\hline$K_{\text {Styp }}$ & $0.71_{(10)}$ & & & & \\
\hline $\mathrm{K}_{\mathrm{Smin}}$ & 0.48 & & & & \\
\hline $\mathrm{K}_{\text {Smax }}$ & 1.2 & & & & \\
\hline \multicolumn{6}{|c|}{ 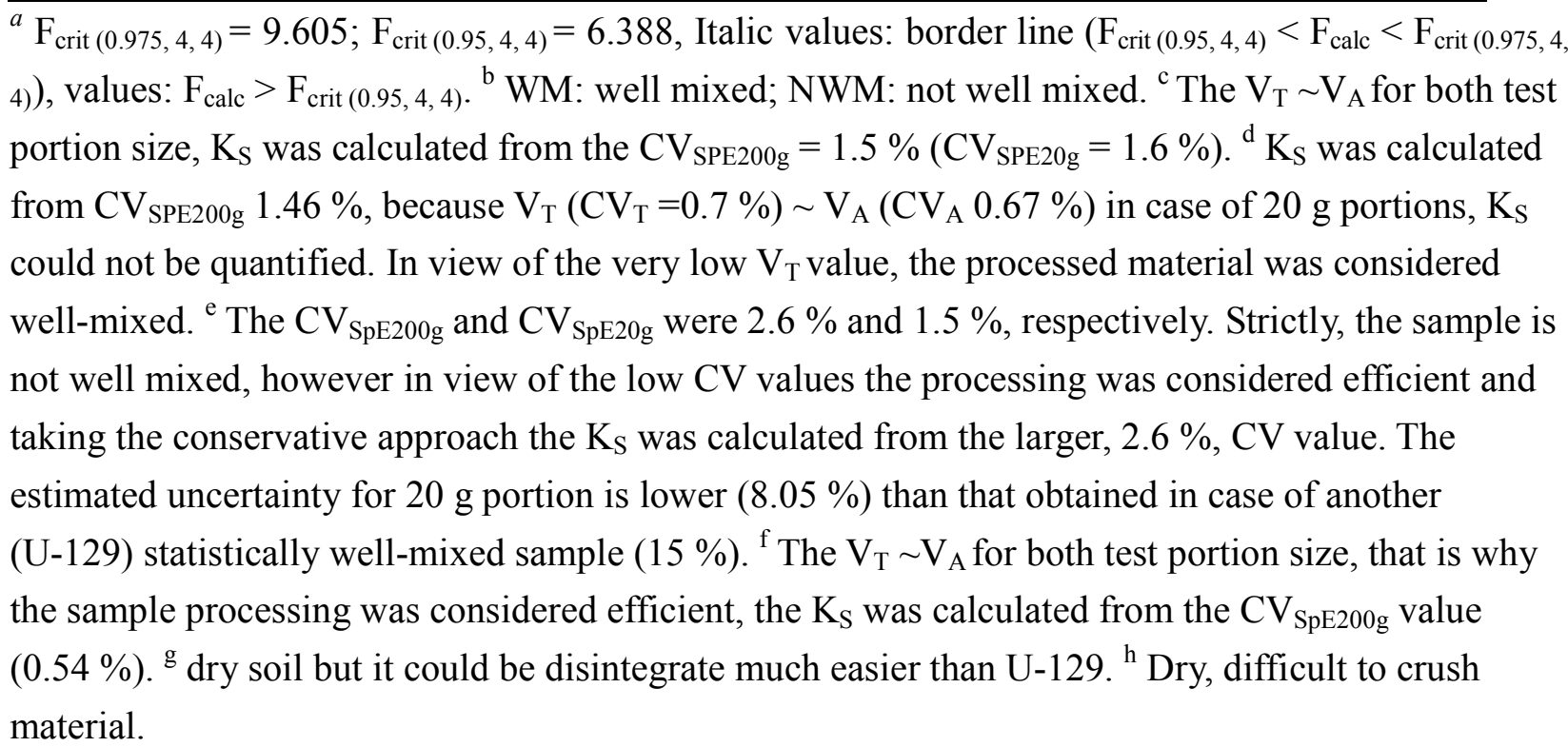 } \\
\hline
\end{tabular}


Table 7. Contribution of main steps to the combined uncertainty of residue data $\left(\mathrm{CV}_{\mathrm{R}}\right.$ and $\left.\mathrm{CV}_{\mathrm{Lab}}\right)$.

\begin{tabular}{|c|c|c|c|c|}
\hline $\mathrm{CV}_{\mathrm{S}}$ & $\mathrm{CV}_{\mathrm{A}}$ & $\mathrm{CV}_{\mathrm{SP}}$ & $\mathrm{CV}_{\mathrm{R}}$ & $\mathrm{CV}_{\mathrm{Lab}}$ \\
\hline 0.25 & 0.15 & 0.01 & 0.29 & 0.15 \\
\hline 0.25 & 0.15 & 0.02 & 0.29 & 0.15 \\
\hline 0.25 & 0.15 & 0.03 & 0.29 & 0.15 \\
\hline 0.25 & 0.15 & 0.04 & 0.29 & 0.16 \\
\hline 0.25 & 0.15 & 0.05 & 0.30 & 0.16 \\
\hline 0.25 & 0.15 & 0.06 & 0.30 & 0.16 \\
\hline 0.25 & 0.15 & 0.07 & 0.30 & 0.17 \\
\hline 0.25 & 0.15 & 0.08 & 0.30 & 0.17 \\
\hline 0.25 & 0.15 & 0.09 & 0.31 & 0.17 \\
\hline 0.25 & 0.15 & 0.1 & 0.31 & 0.18 \\
\hline 0.25 & 0.15 & 0.11 & 0.31 & 0.19 \\
\hline 0.25 & 0.15 & 0.12 & 0.32 & 0.19 \\
\hline 0.25 & 0.15 & 0.13 & 0.32 & 0.20 \\
\hline 0.25 & 0.15 & 0.14 & 0.32 & 0.21 \\
\hline 0.25 & 0.15 & 0.15 & 0.33 & 0.21 \\
\hline 0.25 & 0.25 & 0.01 & 0.35 & 0.25 \\
\hline 0.25 & 0.25 & 0.02 & 0.35 & 0.25 \\
\hline 0.25 & 0.25 & 0.03 & 0.35 & 0.25 \\
\hline 0.25 & 0.25 & 0.04 & 0.36 & 0.25 \\
\hline 0.25 & 0.25 & 0.05 & 0.36 & 0.25 \\
\hline 0.25 & 0.25 & 0.06 & 0.36 & 0.26 \\
\hline 0.25 & 0.25 & 0.07 & 0.36 & 0.26 \\
\hline 0.25 & 0.25 & 0.08 & 0.36 & 0.26 \\
\hline 0.25 & 0.25 & 0.09 & 0.36 & 0.27 \\
\hline 0.25 & 0.25 & 0.1 & 0.37 & 0.27 \\
\hline
\end{tabular}




$\begin{array}{lllll}0.25 & 0.25 & 0.11 & 0.37 & 0.27 \\ 0.25 & 0.25 & 0.12 & 0.37 & 0.28 \\ 0.25 & 0.25 & 0.13 & 0.38 & 0.28 \\ 0.25 & 0.25 & 0.14 & 0.38 & 0.29 \\ 0.25 & 0.25 & 0.15 & 0.38 & 0.29\end{array}$

${ }^{a} \mathrm{CV}_{\mathrm{S}}$ : Uncertainty of sampling; $\mathrm{CV}_{\mathrm{SP}}$ : Uncertainty of sample processing; $\mathrm{CV}_{\mathrm{A}}$ : Uncertainty of analysis; $\mathrm{CV}_{\mathrm{R}}$ : uncertainty of the residue analytical results; $\mathrm{CV}_{\mathrm{Lab}}$ : uncertainty of results of the analysis of a laboratory sample 